\title{
Domestic Partnership
}

National Cancer Institute

\section{Source}

National Cancer Institute. Domestic Partnership. NCI Thesaurus. Code C53262.

Indicates a person who is a member of an unmarried couple, including same sex couples,

living together in longstanding relationships, that are registered or unregistered. 